DOI: $10.17707 /$ AgricultForest.64.4.19

\author{
Otilija SEDLAK*, Radovan PEJANOVIĆ, Zoran ĆIRIĆ, \\ Jelica EREMIĆ-ĐOĐIĆ, Goran ŠKATARIĆ, Ivan BOŠNJAK ${ }^{1}$
}

\title{
PLANNING THE SOWING STRUCTURE APPLYING OPTIMIZATION MODELS
}

\begin{abstract}
SUMMARY
The selection of agricultural plants for sowing and planning the economic success in production is done in conditions of uncertainty and high risk. The factors, which cause the biggest uncertainty in achieving returns in agricultural production, can be quantified by the valuation method. The sense, value, manner and process of decision-making problems are determined by the cultural, social, temporal, value, as well as logical context. Fuzzy logic was developed more than five decades ago. $\mathrm{T}$

he characteristics of fuzzy logic include operating by fuzzy notions, imprecise authentication tables, and fuzzy inference rules. All these characteristics of fuzzy logic are highly important, especially if we try to exchange or supplement the long-dominating approach of decision making in agricultural management with the descriptive one.

The criteria, limitations and performances of measures of alternatives bear in themselves some aspects of indefiniteness: in determinativeness, multiple aspects of meaning, incompleteness and fuzziness. Operational research offers optimization models aimed at finding an activity programme that will yield the best possible results. The models use precisely determined and known data.

Constraints are also precisely determined, and the goal function is clearly defined, so that it can be formulated easily and simply. Reality, especially in the agricultural production, however, is different: very often we lack precise information on the value of individual input parameters, or the values of coefficients in constraint and goal functions, and imprecise formulation of limitations themselves is possible as well.

This paper presents the valuation method at planning the structure of sowing: wheat, chamomile and mint.

Keywords: factors for achieving returns, valuation method, fuzzy systems.

\footnotetext{
${ }^{1}$ Otilija Sedlak* (corresponding author: so0609967@gmail.com), Zoran Ćirić, University of Novi Sad, Faculty of Economics Subotica; SERBIA; Radovan Pejanović, University of Novi Sad, Agricultural Faculty Novi Sad; SERBIA; Jelica Eremić-Đođić, EPS Distribution DOO Beograd / University Edukons, Faculty of Business Economics, Sremska Kamenica, SERBIA; Goran Škatarić, University of Donja Gorica, Podgorica, MONTENEGRO; Ivan Bošnjak, Ministry of the Public Administration and Local Self-Government, Belgrade, SERBIA.

Paper is presented on Green Room Sessions - International Conference, Podgorica 2018

Notes: The authors declare that they have no conflicts of interest. Authorship Form signed online.
} 


\section{INTRODUCTION}

In the early $21^{\text {st }}$ century the extensive use of the resources, fresh water scarcity, and sharp rises in the price of food have become causes for concern (Springer \& Duchin, 2014). In agricultural production, land-use decisions are components of economic planning that result in the strategic allocation of fields (Reinmuth et al., 2017; Peltonen-Sainio et al., 2016). The farmer plans crops for sowing on the basis of available data and experiences. Yield in the next year is determined by quality and farmland size, the structure of husbandry production, machinery supply, and possibility to provide necessary working capital under favourable conditions, adequate labour and climatic conditions (Zhao et al., 2018). The concrete yield of some crop depends on crop rotation, depth of ploughing, quantity of (mineral) fertilizer consumption, herbicide, crop-dusting, seed (grain) sort and quality (Derycke et al., 2014). The cited factors can be quantified. Weighted indexes for some factors can be determined on the basis of data from the previous years. Starting from it, a general model can be designed to determine optimal conditions for husbandry production and expected yield (Hellemans et al., 2018).

For centuries, various researchers have considered whether and how climatic conditions-such as temperature, rainfall, and violent storms-influence the nature of societies and the performance of economies (Carleton \& Hsiang, 2016). Husbandry yields also depend on the climatic conditions as rainfall amount, temperature, the depth of the snow, storms, and so on. The cited factors cannot be easily predicted and quantify in advance. Decisions on crop sowing are made under conditions of uncertainty and high risk caused by:

-Many relevant factors that cannot be measured;

-Instability and nonlinearity of relevant factors;

-Lack of information for quantifying and measuring relevant factors influence;

-Insufficient exactness and information unavailability.

The method based on the unique evaluation of criteria will be applied for solving the cited uncertainties in husbandry. The evaluation method can be applied if the criterion values can be treated as estimates or it can be transformed into them.

The evaluation method is similar to R. Jain's method of arrangement (Jain, 1977) that is based on the weighted estimate aggregating. As estimate processing can be described with the help of many rules, the method forms the fuzzy set of extra estimates using aggregation based on the rules, and it can be also programmed as a fuzzy system (Jia et al., 2018).

In the Republic of Serbia, the existing infrastructure and systems of knowledge transfer are not effective enough and they fail to meet the needs of dynamic development of the agricultural sector (Sedlak et al., 2016). 


\section{MATERIAL AND METHODS}

\section{Characteristics of the Method for Evaluating Uncertainty Factors}

To apply the method, it is necessary to arrange alternatives described by many criteria, where the values of criteria are fuzzy sets (Kosko, 1995). To treat the problem simpler, we chose the unique, five-degree way of criteria description. The same fuzzy set given by a triangular fuzzy number was associated to every estimate. This way of a unique criterion description enabled to evaluate variants in the way usual in education. This evaluation considers every criterion, with all possible values, and the result can be used as a basis for variant evaluating.

The characteristics of the method appear in the following way (Sedlak, et al., 2005):

1.We describe different criteria by the same estimates, but the identical, gradual evaluation is not necessary in all criteria.

2.Estimates are defined by fuzzy sets where their belonging functions show the middle estimates of the estimates set in the belonging degree. Besides, they must point to the fact that the middle estimates and values, being in their immediate environment (for example, $1.5 ; 2.5 ; 3.5$, and so on) belong to two neighbouring sets. The estimate set (supp) can be determined by the interval which is, for example, the estimate -0.6 , the estimate +0.6 . From the interval $\mathbf{p}$, the neighbouring ones have the mutual part. The belonging function of fuzzy estimate set is the symmetrical function which in the middle of the interval takes the value 1 , and from the middle in both directions, it is monotonous falling. The choice of the appropriate function can be found on the basis of a poll or on the basis of looking for an approaching function. We made the choice on the basis of looking for an approximate function. So, to describe the belonging function, we chose the triangular fuzzy number (we chose the triangular for the belonging function for every estimate).

3.To realize the average which can be considered to be the estimate, the result is given to $\mathbf{p}$-estimates. The $\mathbf{p}$ value determines the highest degree of evaluation, which is applied with criteria. Let's call this set, consisting of $\mathbf{p}$ estimates, the set of results. In that case, the sum of weighted estimates will be some subset of the set of results (let's call it the set of extra estimates). The centre of gravity of this subset corresponds to the average.

4. To consider the centre of gravity the estimate, we have to determine the rule by which the estimates describing alternatives will be copied on the estimates in the set of results.

The following rules are necessary:

- One subset of the same estimate in the set of results is associated to every estimate. The belonging function of the subset is also the triangular fuzzy number.

-Every estimate exerts influence on the result to the degree corresponding to the gravitational value of criteria that belongs to it (maximal 
gravitational value is 1). However, it should be noted that only criteria with higher gravitational values can exert influence on the final result (Yager's level set method assumes the same). We can attain if we multiply the height of the subset by the square of the gravitational value.

-If more criteria get the same estimate, we associate different subsets in the set of results of the same estimate to the estimates multiplied by different weighted indexes.

-Aggregating obtained subsets with the estimate copying (t-konorma) in the set of results, we get the set of extra estimates. The centre of set gravity of extra estimates, i.e. the projection on the x-axis can be considered as an estimate.

The formal similarities between Jain's method and the mark-giving method are used for comparing (formerly applied signs are used in comparing).

Steps of Jain's method: (Jain, 1977)

1. One $R_{1}$ fuzzy set is formed for every $a_{i}$ alternative in the form:

$$
R_{i}=\sum_{j=1}^{m} g_{j} \cdot r_{i j}
$$

where $g_{i}$ is the fuzzy set of weights, $r_{i j}$ is the fuzzy value $K_{i}$ of criteria in case of a: alternative (signed operations mean the multiplication and addition of fuzzy sets).

2. A union of multiples of $R_{i}$ sets is formed:

$$
S=\bigcup_{i=1}^{n} \text { sup } \mathrm{R}_{\mathrm{i}}
$$

and one 'maximized' $\mathrm{M}$ fuzzy set is defined in the set $\mathrm{S}$ :

$$
\mu_{M}(r)=\left[r / r_{\max }\right]^{\beta}
$$

with the function of belonging, where $r_{\max }=$ sup $S$ and $\beta$ is a natural number (the set M gives the upper limit for the values $\mu_{R_{i}}{ }^{(r)}$.

3. A fuzzy set $\mathrm{R}_{\mathrm{io}}$ is formed from $\mathrm{M}$ and $\mathrm{R}_{\mathrm{i}}$ sets with the functions belonging to:

$$
\mu_{R_{i 0}}(r)=\min \left\{\mu_{R_{i}}(r), \mu_{M}(r)\right\},(r \in S)
$$

4. One $Y_{i}$ value is assigned to every alternative:

$$
y_{i}=\max \mu_{\mathrm{R}_{\mathrm{io}}}(\mathrm{r}),(\mathrm{r} \in \mathrm{S})
$$

Many have criticized Jain's method as it does not give any help in forming the set $M$ (choice $\beta$ ), and $Y_{i}$, which is assigned the alternative $a_{i}$, represents only one maximum value (the other ones are not taken into consideration in ordering). 
Comparing to Jain's method, the steps of this method are the following:

1.Like in Jain's method, one $R_{i}$ fuzzy set is formed for every $a_{i}$ alternative in the form:

$$
R_{i}=\sum_{j=1}^{m} g_{j} \cdot r_{i j}
$$

where the values of the weight $g_{j}$ can range within the interval $(0,1)$ of real numbers, the values $r_{i j}$ are special, and the fuzzy sets of marks are the same for every criterion (the degree of marks can be different depending on the criteria).

2-3. The method does not limit the values of functions of belonging to the sets $R_{i}$, it is not necessary to define $M$, nor form $R_{i o}$ sets. Instead, the sets $R_{i}$ are compared in the mutual E set.

4. The value $y_{i}$, which joins the alternative $a_{i}$, representing the centre of gravity, is formed taking into consideration all the values of criteria. The value $\mathrm{y}_{\mathrm{i}}$, shows the ordinal number of alternatives.

We can conclude that the mark-giving method, compared to Jain's method, represents a different principle of problem solving.

Taking into consideration every value of the "possibility of realization", Yager's method (Yager, 2005) assigns the value $Y_{i}$ to the alternative $a_{i}$.

$$
y_{i}=\max \min \left(\mu_{\mathrm{k}_{\mathrm{j}}}\left(\mathrm{a}_{\mathrm{i}}\right) \mathrm{t}_{\mathrm{j}}\right)
$$

It also orders every $K_{j}(\leq j \leq m)$, as well as alternatives on the basis of the value $Y_{i}$. Yager's method does not always differentiate between alternatives with approximately the same weight, so it assigns the same numerical values to the groups of alternatives. With the mark-giving method we notice quite the opposite: it assigns a different numerical value to almost every alternative. According to this, the mark-giving method points more to the difference between alternatives than Yager's method (Zhao et al., 2018; Sedlak and Ćirić, 2007). The application of certain methods we can find in the scientific papers of Yager and Zadeh (Yager and Zadeh, 2012). As we mentioned the yield of some crop depends on crop rotation, depth of plowing, quantity of (mineral) fertilizer consumption, herbicide, crop-dusting, seed (grain) sort and quality. In a given field a decision about selection of sowing was done on the basis of the conditions under consideration that it is best to choose: chamomile, mint and wheat.

\section{RESULTS AND DISCUSSION}

\section{The Choice of Sowing Crop by the Evaluation Method}

Three crops are planned for sowing: chamomile, mint and wheat. But, it is necessary to select only one taking into consideration factors exerting influence 
on yield, therefore on our decision about the choice of crop for sowing. Based on the long-range research of experts, and farmers' working experiences (considered experts in this field), we chose 15 most important factors enabling yield planning in relation to immeasurable criteria. The experts are experts of field and plant production. They provide advisory services in the field of plant production, studying cultural plants and their cultivation. It is generally concerned with landscaping for high and high profitable production, composition of a herbal product and soil cultivation, and special cultivation deals with the reigning of crop cultures, explores their botanical, biological and ecological characteristics. The experts have expertise in agriculture and they task includes providing advisory services growing of vegetable plants.

These factors represent the limitations; therefore we called them the main criteria and relating to the strength of their possible influence, we added them the weighted indexes. Weighted indexes are determined on the basis experts' experiences. To their opinion, yield of some crops depends on different factors, in different extent. Table 1 includes criteria and their assumed weighted indexes. These factors were picked up by the experts, as their indexes also.

Table 1. Criteria and their weighted indexes

\begin{tabular}{|l|c|}
\hline \multicolumn{1}{|c|}{ Criteria } & $\begin{array}{c}\text { Weighted } \\
\text { index }\end{array}$ \\
\hline 1. Forming market prices of agricultural crops & 1,00 \\
\hline 2. Crop rotation & 0,90 \\
\hline 3. Condition of land & 0,80 \\
\hline 4. Work safety of machines and connecting machines & 0,70 \\
\hline 5. Choice of plant sort (sort or hybrid) & 0,50 \\
\hline 6. Seed germination and seedling quality & 0,31 \\
\hline 7. Prompt execution of technological operations & 0,25 \\
\hline 8. Quality of mineral and organic fertilizers & 0,24 \\
\hline 9. Quality of protective measures & 0,22 \\
\hline 10. Diseases of plants and pests & 0,21 \\
\hline 11. Air and land temperature & 0,19 \\
\hline 12. Reliability of weather forecasts & 0,16 \\
\hline 13. Precipitation (rain, snow, fog, hail, hoar frost, dew, freezing rain...) & 0,15 \\
\hline 14. Climatic conditions & 0,14 \\
\hline 15. Labour costs & 0,11 \\
\hline
\end{tabular}

Table 2 includes the description of yield of some crops with the help of estimates regarding to the criteria. The estimate points to the influence of some criteria (1-15) on crop yield; it ranges from five (big influence) to zero (no influence). For example, suppose that labour costs for soil cultivation (criterion 15) has no influence on any considered crop, while the policy of market pricing, as one of factors having influence on sowing, is evaluated by the highest estimate with all tree crops. 
Table 2. Yield relation of some crops under influence of different criteria

\begin{tabular}{|l|l|l|l|l|l|l|l|l|l|l|l|l|l|l|l|}
\hline $\begin{array}{l}\text { Crop } \\
\text { criterion }\end{array}$ & 1. & 2. & 3. & 4. & 5. & 6. & 7. & 8. & 9. & 10. & 11. & 12. & 13. & 14. & 15. \\
\hline Chamomile & 5 & 5 & 4 & 4 & 4 & 4 & 4 & 3 & 3 & 1 & 3 & 3 & 3 & 4 & 0 \\
\hline Mint & 5 & 5 & 3 & 4 & 4 & 5 & 4 & 3 & 3 & 2 & 3 & 3 & 3 & 4 & 0 \\
\hline Wheat & 5 & 5 & 4 & 5 & 5 & 4 & 3 & 3 & 3 & 3 & 3 & 3 & 3 & 3 & 1 \\
\hline
\end{tabular}

The obtained results are processed according to the advance established rules, which are cited in detail at the beginning of the work (according to the rules of the evaluating method). These results represent the estimate of crop uncertainty. The better result is, the bigger uncertainty in realizing the planned yield, and reversely.

Table 3. Result of arrangement

\begin{tabular}{|l|c|}
\hline Crop & Results of the evaluation method \\
\hline Chamomile & 4,01 \\
Mint & 3,96 \\
Wheat & 3,51 \\
\hline
\end{tabular}

According to this estimate, it can be concluded that (Table 3.) the influence of factors that are indefinite, immeasurable are at the same time the strongest on chamomile, and it points to the fact that its sowing is with the highest risk. Risk with wheat is the lowest (Jakovčević et al., 2014).

However, if the decision on the choice of crop is made on the basis of economic indicators only (Table 4.), chamomile turns to be economically the most acceptable from the standpoint of realized profit per $\mathrm{kg}$ (Table 5.) and profit rate (Table 6).

Table 4. Average yield of crops and income, in $€$

\begin{tabular}{|c|c|c|c|}
\hline Crops & Yield kg/ha & Redemption price & Income \\
\hline 1 & 2 & 3 & $4(2 \times 3)$ \\
\hline 1. Chamomile & 8.000 & 0,17 & 1.330 \\
\hline 1.1. flower & 3.000 & 0,26 & 780 \\
\hline 1.2. herb & 5.000 & 0,11 & 550 \\
\hline 2. Mint & 25.000 & 0,11 & 2.729 \\
\hline 2.1. first year leaf & 5.100 & 0,17 & 867 \\
\hline 2.2. first year herb & 9.900 & 0,08 & 792 \\
\hline a) First year/total & 15.000 & 0,11 & 1.659 \\
\hline 2.3. second year leaf & 3.000 & 0,17 & 510 \\
\hline 2.4. second year herb & 7.000 & 0,08 & 560 \\
\hline b) Second year/total & 10.000 & 0,11 & 1.070 \\
\hline 3. Wheat & 5.500 & 0,18 & 990 \\
\hline
\end{tabular}


Table 5. Direct production costs per hectare with farmers, in $€$

\begin{tabular}{|l|r|r|r|r|}
\hline \multirow{2}{*}{ Elements } & \multirow{2}{*}{ Chamomile } & \multicolumn{2}{|c|}{ Mint } & \multirow{2}{*}{ Wheat } \\
\cline { 3 - 4 } & & 1 year & 2 year & \\
\hline 1. Tilling and sowing & 130,00 & 151,50 & - & 200,00 \\
2. Seed - planting material & 208,50 & 810,50 & - & 26,50 \\
3. Mineral fertilizer & 105,50 & 193,50 & 183,00 & 313,50 \\
4. Care and crop protection & 20,50 & 33,50 & 15,00 & 30,50 \\
5. Crop - dusting & 15,00 & 12,00 & 12,00 & 16,00 \\
6. Combining (I+II) & 165,50 & 80,00 & 80,00 & 112,50 \\
7. Crop transport & 80,00 & 96,00 & 65,00 & 130,00 \\
\hline 8. Total & 725,00 & $1.377,00$ & 355,00 & 829,00 \\
\hline 9. Average costs per kg. & 0,09 & 0,07 & 0,15 \\
\hline 10. Selling price & 0,17 & 0,11 & 0,18 \\
11. Profit per kg (10 -9) & 0,08 & \multicolumn{2}{|c}{} \\
\hline
\end{tabular}

Note: Account in current prices

Table 6. Economic production indicators per hectare in crops, in $€$

\begin{tabular}{|c|c|c|c|c|c|c|}
\hline Erops & Income & Costs & Profit & $\begin{array}{c}\text { Engaged } \\
\text { capital }\end{array}$ & $\mathrm{K}_{\mathrm{e}}{ }^{2}$ & do’ (\%) \\
\hline 1 & 2 & 3 & 4 & 5 & $6(2: 3)$ & $7(4: 5)$ \\
\hline Chamomile & 1.330 & 722 & 608 & 6.270 & 1,84 & 9,70 \\
\hline $\begin{array}{l}\text { Mint } \\
\text { First year }\end{array}$ & 1.659 & 1.377 & 282 & 6.770 & 1,20 & 4,17 \\
\hline $\begin{array}{l}\text { Mint } \\
\text { Second year }\end{array}$ & 1.070 & 353 & 717 & 5.760 & 3,03 & 12,45 \\
\hline Total & 2.729 & 1.730 & 999 & 12.530 & 1,58 & 7,98 \\
\hline Average & 1.365 & 865 & 500 & 6.265 & 1,58 & 7,98 \\
\hline Wheat & 990 & 828 & 162 & 6.800 & 1,20 & 2,38 \\
\hline
\end{tabular}

\section{CONCLUSIONS}

The main conclusion that can be drawn is that the efficient economic sowing plan, at any level of investment, is providing the minimal realization of risk level and that the crop yields depend on many measurable and immeasurable factors.

The models for determining the optimal structure of agricultural production is possible to set with analysing the measurable factors. Here is very important to examine in all production phases the reliability of factors that ate causing yields. The economic analysis does not quantify the influence of uncertainty which can have the decisive influence on the realized yields in agricultural production. The decision on the choice of the crop is made based on the economic indicators shown that only chamomile turns to be economically the most acceptable from the standpoint of realized profit.

\footnotetext{
${ }^{2} K_{e}$ - rate/coefficient of return; do'- profit rate.
} 
From the point of the immeasurable factors, the fuzzy method includes many competitive and conflict criteria in a relatively simple way. Certain qualities of the applicants can't be measured accurately, and an expert's opinion is needed, although the expert might have doubts or hesitate to give a final position. In principle the method of evaluation can be generally used, and if the values of the criteria can be treated as estimates (or can be transformed into them), the method is applicable.

The applied fuzzy evaluating method that was based on giving of the marks allows the arrangement of such alternatives, where the fuzzy criteria can be described by estimates, or where the values of the criteria can be considered as estimates. The results are similar to the results achieved by other methods of evaluation. The "mark giving method evaluation method" criteria are treated as a fuzzy system with aggregates aggregation. The method in some of its points bears a resemblance to the method of editing an alternative to R. Jain. The weight-based editing associated alternatives, is with the different principle than one used by Jain. The weight-based editing associated alternatives, is with a different principle than that used by Jain. The method that ranks alternatives using fuzzy logic and fuzzy systems can be addressed in a relatively simple way with a large number of competitive and conflicting criteria. The main point of this study was in presenting a new approach in decision making and mark giving and this may constitute the object of future studies.

\section{REFERENCES}

Carleton, T.A., Hsiang, S.M. (2016): Social and economic impacts of climate. Science. 9; 353 (6304). pii: aad9837.

Derycke, V., Latré, J., Van De Vijver, E., De Roo, B., De Cauwer, B., Haesaert, G. (2014): Weed population in relation to crop rotation and nitrogen fertilisation. Communications in agricultural and applied biological sciences. 79(2): 71-9.

Hellemans, T., Landschoot, S., Dewitte, K., Van Bockstaele, F., Vermeir, P., Eeckhout, M., Haesaert, G. (2018): Impact of Crop Husbandry Practices and Environmental Conditions on Wheat Composition and Quality: A Review. J Agric Food Chem. 2018 Mar 21;66(11):2491-2509. doi: 10.1021/acs.jafc.7b05450. Epub 2018 Feb 28.

Jain, R. (1977): A Procedure for Multiple-aspect Decision Making Using Fuzzy Sets. International Journal of System Science, Vol. 8, No. 1, 1-7.

Jakovčević, K., Sedlak, O., Ćirić, Z. (2014): Models of analyzing the influence of factors on profit rate formation. Industrija, Ekonomski institut, Beograd, Vol. 42, Iss.1, 42 (1), 7-26.

Jia, B., Hao, L., Zhang, C., Chen, D. (2018): A Dynamic Estimation of Service Level Based on Fuzzy Logic for Robustness in the Internet of Things. Sensors (Basel). 2018 Jul 7;18(7). pii: E2190. doi: 10.3390/s18072190.

Kosko, B. (1995): Neural Networks and Fuzzy Systems. New York: Englewood Cliffs, Prentice Hall, Inc.

Peltonen-Sainio, P., Jauhiainen, L., Lehtonen, H. (2016): Land Use, Yield and Quality Changes of Minor Field Crops: Is There Superseded Potential to Be Reinvented in Northern Europe? PLoS One. 21;11(11):e0166403. doi: 10.1371/journal.pone.0166403. eCollection. 
Reinmuth, E., Parker, P., Aurbacher, J., Högy, P., Dabbert, S. (2017): Modeling perceptions of climatic risk in crop production. PLoS One;12(8):e0181954. doi: 10.1371/journal.pone.0181954.

Sedlak, O., Ćirić Z. (2007): Fuzzy Risk Management for Project Financing. Strategic Management and Decision Support Systems in Strategic Management - Risk Management in Strategic Management (p. 42). Subotica: Faculty of Economics Subotica.

Sedlak, O., Jakovčević, K., Ćirić, Z. (2005): Planning the Sowing Structure Applying the Method for Uncertainty Valuation. YUMTO Novi Sad (p. 122). Novi Sad: Agricultural Faculty of Novi Sad.

Sedlak, O., Jovin, S., Pejanović, R., Ćirić, Z., Eremić, Đ.J. (2016): Micro, Small and Medium Business Units in Serbian Agribusiness. Journal Economics of Agriculture, Vol. LXIII, No4, UDC 338.43:63, ISSN 0352-3462 , 1219-1235.

Springer, N.P., Duchin, F. (2014): Feeding nine billion people sustainably: conserving land and water through shifting diets and changes in technologies. Environ Sci Technol. 15; 48(8): 4444-51. doi: 10.1021/es4051988. Epub 2014 Apr 4.

Yager, R. R. (2005): Fuzzy Decision Making Including Unequal Objectives. Fuzzy Sets and Systems 1, 2005 , 87-95.

Yager, R. R., Zadeh, L. A. (2012): An Introduction to Fuzzy Logic Applications in Intelligent Systems. Springer Science \& Business Media.

Zhao, J., Zhan, X., Jiang, Y., Xu, J. (2018): Variations in climatic suitability and planting regionalization for potato in northern China under climate change. PLoS One. 27;13(9): e0203538. doi: 10.1371/journal.pone.0203538. eCollection 2018.

Zhao, L., Han, Z., Yang, J., Qi, H. (2018): Single seed precise sowing of maize using computer simulation. PLoS One. 2018 Mar 5;13(3):e0193750. doi: 10.1371/journal.pone.0193750. eCollection 2018. 